\title{
Correction to: Shape Dependence of Acoustic Performances of Buildings with a Hyperbolic Paraboloid Cable Net Membrane Roof
}

\author{
Fabio Rizzo ${ }^{1}$ - Paolo Zazzini ${ }^{1}$
}

Published online: 29 November 2017

(c) Australian Acoustical Society 2017

\section{Correction to: Acoust Aust (2017) 45:421-443 https://doi.org/10.1007/s40857-017-0092-9}

In the original article, the reference Rizzo and Ricciardelli (2017) was incorrectly published. The invalid reference and the corrected reference are given below:

Invalid reference: Rizzo, F., Ricciardelli, F.: Aeroelastic wind tunnel tests of cable net roofs with square plan dimensions, accepted for publication. J. Wind Eng. Ind. Aerodyn. 139, 153-169 (2017)

And should be corrected to

Rizzo, F., Ricciardelli, F.: Design approach of wind load for hyperbolic paraboloid roof with circular and elliptical plan. J. Eng. Struct. 139, 153-169 (2017)

The original article can be found online at https://doi.org/10.1007/ s40857-017-0092-9.

$\triangle$ Fabio Rizzo

fabio.rizzo@unich.it

1 Department of Engineering and Geology, University of G.

D’Annunzio, Chieti-Pescara, Viale Pindaro 42, 65100

Pescara, Italy 